\title{
LEARNING THE CHINESE SCRIPT CAN BE EASY1
}

\author{
Yao Shen \\ University of Michigan
}

Learning to speak Chinese can be difficult; learning to speak and to read Chinese at the same time is definitely not easy; learning to speak, to read, and to write in Chinese, all three at the same time, is probably what has given Chinese its reputation as a difficult language. The difficulty, however, is not that Chinese is difficult to speak, to read, or to write; rather, it often lies in the way Chinese has been taught. And bad teaching can have many causes. Perhaps the teacher is not able to show the students in what specific areas Chinese is different from their native language. Sometimes the teacher shows the students the difference but does not drill them enough for them to form the necessary new skills. Often the instructor is teaching endless items in the language in an unorganized manner and therefore the students find it difficult to remember them. Quite frequently the teacher is giving instruction in too many subjects: in speaking, in reading, and in writing simultaneously. Any one of these can give the learner the mistaken impression that the language is difficult. He does not realize that perhaps the techniques are responsible for the difficulties in the learning process.

The purpose of this article is to show that learning to write in Chinese can be made easy. Three related points are discussed below. The first one is to make learning to write the sole new thing the students are undertaking. In other words, writing should not be carried on simultaneously with speaking and reading. Students should be taught to speak first. While learning to speak they establish new oral habits. After the new oral habits are established they learn to read. During the reading process, students must no longer be struggling with strange phonological, morphological, or syntactical features.

${ }^{1}$ This was a paper delivered at the winter meeting of the Michigan Linguistic Society held at Wayne State University, Detroit, Michigan, 1956. 
Their reading should be confined to what they already can say. The only new thing in the reading process is the association of the sound with the graphic symbols, the oral production of which is already part of their established habits. Once the students are able to read, they learn how to write. When they are learning how to write, they should not have to struggle with the control of the speech organs or associating sounds with the graphic representations. They should write what they already know how to read. To write is to acquire skill in reproducing what they have seen in reading. It calls for new habits in manipulating the wrist and the fingers, and writing in directions different from those in their native language. If speaking, reading, and writing are all introduced at the same time, the students must, in effect, acquire new oral habits, associate these new oral habits with new graphic representations, and associate these complexes with new writing habits. The situation is not unlike that confronting a layman who must learn to sing, to recognize music notes, and to play an instrument at the same time.

Learning to speak first, to read next, and to write last is a justifiable sequence in language learning. In the learning process generally, recognition precedes production. Applied to language, this means that hearing (recognition) comes before speaking (production); reading (recognition) comes before writing (production). Students at the point of learning to write should recognize what they are going to write. Furthermore, this order of speaking, reading, and writing has a psychological advantage. After the students are able to speak, they are anxious to read. Often they are impatient. Once they know how to read, there is no way of stopping them from wanting to write in Chinese. Once they have learned how to write in Chinese, the only thing that is left to satisfy this recurrent thirst is to teach them how to write with a Chinese brush. No one would deny that to establish any set of new habits is a difficult task. But when the desire to learn comes from the learner, to overcome difficulties becomes a satisfaction in achievement.

The second point is that the teacher can point out to the students the recurrent partials in various written forms which they already recognize, as a pronunciation teacher does with the recurrent partials in oral production. Learning to write can be compared with learning to speak. They are the same in that both are productive activities and both require new habits in production. The differences are: to speak calls for the 


\section{LEARNING THE CHINESE SCRIPT CAN BE EASY}

use of the speech organs, and to write calls for the use of the wrist and the fingers; the former involves production of what is heard, and the latter involves production of what is seen.

Let us now adopt the procedure employed in linguistics in analyzing the sound system of a language to dissect the writing system of Chinese. We can compare the features of sounds in English with the written parts in complete Chinese $\mathrm{dz}$ (characters). 2 The four sounds in English chosen here are:

$/ \mathrm{t} / / \mathrm{k} /$

$/ \mathrm{d} / \mathrm{g} / \mathrm{g}$

$/ \mathrm{t} /$ and $/ \mathrm{k} /$ are the same in that both are fortis and voiceless, both can be accompanied by aspiration, and both are stops. They are different in that the tongue position for $/ t /$ is alveolar, and the tongue position for $/ k /$ is velar. $/ d /$ and $\mathrm{lg} /$ are the same in that both are lenis and voiced, both can occur with minimal aspiration, and both are stops. They are different in that the tongue position for $/ d /$ is alveolar, and the tongue position for $/ g /$ is velar. $/ t /$ and $/ d /$ are the same in that both are alveolar stops. They are different in that $/ t /$ is fortis and voiceless, and $/ d /$ is lenis and voiced. $/ k /$ and $/ \mathrm{g} /$ are the same in that both are velar stops. They are different in that $/ \mathrm{k} /$ is fortis and voiceless, and $/ \mathrm{g} /$ is lenis and voiced.

The four Chinese $d z$ chosen here are:
a. -
b. $=$
c. \pm
d. 7

- and = are the same in that both have -

They are different in that $=$ has another horizontal stroke that - does not have. \pm and $\Psi$ are the same $2 \mathrm{dz}$ or character is the term used to designate a written form in Chinese
that occupies a square of space. 
LANGUAGE LEARNING VOL. VII, 1 \& 2 in that both have \pm . They are different in that $\mp$ has another horizontal stroke which \pm does not have. - and \pm are the same in that both have They are different in that $\_$has a cross which does not have. $=$ and $\mp$ are the same in that both have $=$. They are different in that $\mp$ has a cross which $=$ does not have.

We can compare the occurrences of sounds in English words with the occurrences of written parts in complete Chinese $\mathrm{dz}$. In getting the occurrences of sounds, we shall discover that sounds recur. In getting the occurrences of written parts, we shall also discover that written parts recur. Let us use some utterances in English and some utterances in Chinese to discover such recurrent parts. The English examples are given first.

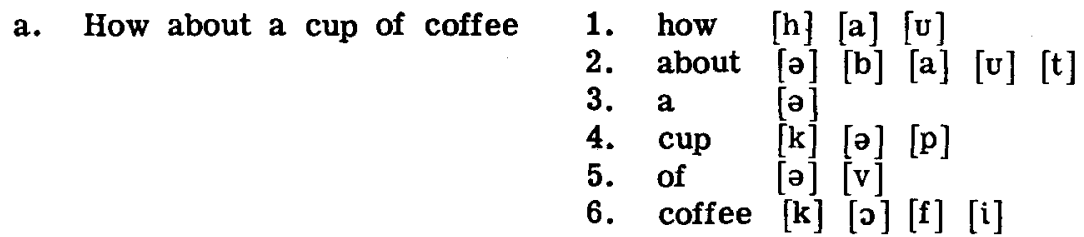

b. Just the thing I'd like 1 . just [j] [o] [s] [t]

2. the [б] [a]

3. thing $[\theta][\mathrm{I}][\mathrm{y}]$

4. I'd [a] [I] [d]

5. like [l] [a] [I] [k] 
The recurrent partials are: $[a][u][a][t][k][x]$.

Let us assume that the students already recognize the following Chinese utterances in the written forms, and we will discover the recurrent partials in these utterances.
a. 你好吕馬
1. 你化↔
2. 女子女子
3. 啨嵒需

b. 他 也 吃

1. 他

2. 也

3. 吃 ロ 乙

c. 极 $3+$ 個人

1. 栍小大人人

2. 33

3. $t+$

4. 估 而 $\square+\square$

5.人从

The recurrent partials are: 1 口 $ん+$

The arrangement of the recurrent sounds in English words can be compared to that of the recurrent parts in Chinese $\mathrm{dz}$. A spoken word in English is made up of a series of sounds. 


\section{LANGUAGE LEARNING VOL. VIII, 1 \& 2}

The difference among words is made by contrastive sounds or different sequences of sounds. For example:
a. kitten / krtan/
kitchen /kičən/
chicken /črkan/

b. $\begin{aligned} & \text { keep } / \mathrm{kip} / \\ & \text { peak } / \mathrm{pik} /\end{aligned}$
c. sue /su/
two /tu/
rue $/ \mathrm{ru} /$
stew /stu/
true /tru/
strew /stru/

The construction of Chinese written $\mathrm{dz}$ can also be analyzed in the same way. $\mathrm{dz}$ can differ from each other due to the different arrangement of various parts. For example:
a. 來 才人人人
b. $\square+\square$
c. 古十人口
d. 李 + 人子
e. 好女子
f. 妾
g. 交 $\leadsto 3$ 
There are hundreds of $\mathrm{dz}$ that are grouped together according to the recurrent partials in the following way:
a. 榆桐
b. 渝洞

Many orientalists designate a limited number of recurrent partials as the determiner parts and others as the phonetic parts. The determiner furnishes the students information as to the place in the dictionary where the $\mathrm{dz}$ can be found. The phonetic often gives the pronunciation of the $\mathrm{dz}$. A few illustrations are given below:

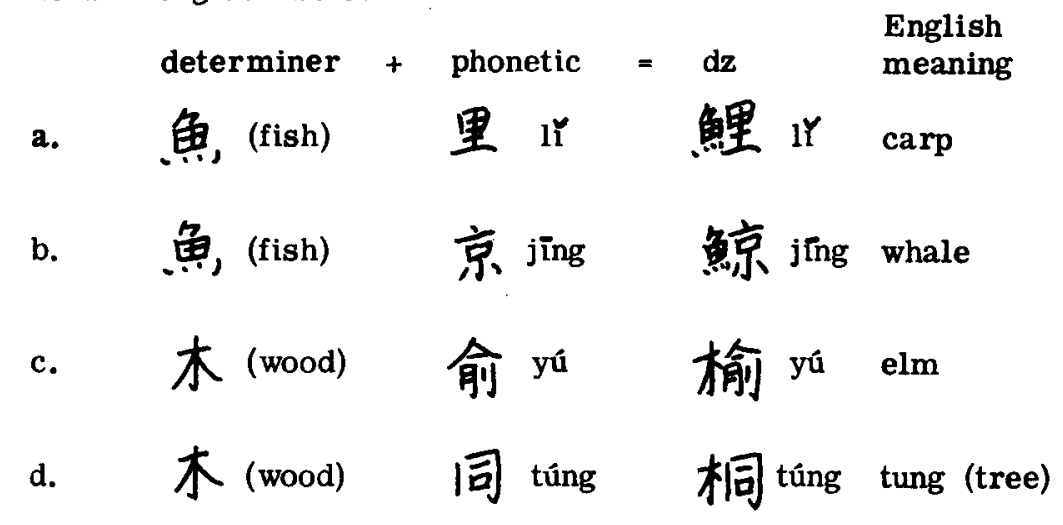

In a stream of speech, sound segments follow one another. Consequently, the representations of such sound segments in a language such as English is temporal. In writing, such as Chinese, a part of a dz can be placed to the top or the bottom, to the right or the left, or to the inside or the outside of the rest of the dz. $\square$ is given here as an example:
a. top 呆
bottom 杏
b. right 知
left 


\section{c. inside outside 太}

Let us use $\square$ again and explore other possible arrangements. Some of the results are listed below:
a.<smiles>[C]1CC1</smiles>
b. 吕
c.
d. 品星
e.

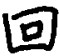
f.

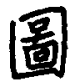

This relationship among the various parts in a Chinese written $\mathrm{dz}$ can also be compared to the letters in the English alphabet. A person whose native script is not like the alphabet in English can also be taught to recognize the recurrent partials and the arrangement of the recurrent partials in relation to certain members of the alphabet. The English letters $o$ and $b$ may be considered to have $o$ as the recurrent partial. $\bar{T}$ The difference is that $b$ has a ve $\bar{r}$ tical bar and o does not. The recurrent partials in $b$ and $d$ are the $o$ and the vertical bar. But in $b$ the vertical bar stands to the left of the o, and in $d$ the vertical bar stands to the right of the $o$. The recurrent partials in $\underline{b}$ and $\underline{p}$ are the $\underline{o}$ and the vertical bar. And in both $b$ and $p$, the vertical bar stands to the left of the $o$. But in $\vec{b}$ the vertical bar extends above the $\underline{o}$, and in $\underline{p}$ the vertical bar extends below the $o$. For $p$ and $q$, again the recurrent partials are the $o$ and the vertical bar. And in both the vertical bar extends below the o. But in $p$ the vertical bar stands to the left of the $\underline{o}$, and in $\underline{q}$ it stands to the right of the $o$. The recurrent partials in $q$ and $d$ are the $o$ and the vertical. In both, the bar stands to the right of the $\overline{0}$. But in 
$q$ the bar extends below the $o$, and in $d$ the bar extends above the $o$. Thus we have $o, \underline{b}, \underline{d}, \underline{p}$, and $\underline{q}$, constituting different arrangements of but two recurrent partials.

Now this is exactly the traditional way of teaching Chinese writing, developed through centuries of experience, and being admirably adapted to the nature of Chinese script. It makes the teaching of writing closely parallel to the teaching of letter recognition in English. The eight elementary strokes have their own names just as each letter in the English alphabet has a name. Then the learner is told to put each of them, left, right, over, or under the stroke written previously. A whole cluster of strokes also has a name (and usually a meaning). When this cluster recurs in other $d z$, such a "partial" is called by its name.

Chinese children in learning how to write get their instructions in just this "spell out" method.

Example 1:

A. How do you write wung meaning king?

B. Three horizontal strokes and one vertical one.

A. $x$

Example 2:

A. What's the head of hwang meaning yellow?

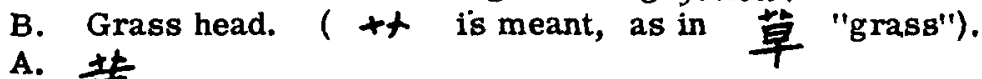

A. 枝

Literate Chinese often obtain information the same way.

Example 3:

A. What's the left side of $y \not{A}$, the monosyllabic name for Chungking? I don't mean the elm-tree $y u$.

B. Three-dot water.

A. 渝

My family name is not very common outside my home region. Recentiy a stranger did not quite catch my name when I intro- 
duced myself, so I said: "Shěn. Three-dot-water Shěn."

This "spell out" method is a common practice in distinguishing family names that are homonyms. In the Shanghai dialect, the family names 王 and 黄 are both pronounced wóng.

Example 4:

A. What's your family name?

Wóng.

B. Wóng. Three-horizontal-strokes-and-one-vertical

A. 王

Example 5:

A. What's your family name?

B. Wóng. Grass-head Wong.

A. 步

This similar practice is found among speakers of English.

Example 6:

A. What's your family name?

B. / stivensan/ spelled with an e. Oh, yes: and with $\underline{\mathrm{v}}$, and not ph.

A. Stevensen.

Example 7:

A. What's your family name?

B. /gre/ spelled with an e.

A. Grey

The third point is that aside from showing the students the recurrent partials and the arrangements of the recurrent partials, the teacher in giving instructions on how to write in Chinese follows a certain procedure. The first step is how to hold the pen. After the pen is held in the appropriate manner, they practise making circles from left to right over the top in order to effect a coordination of wrist and fingers different from that to which they are habituated. When such coordination has been mastered, they must next become accustomed to the normal direction and order of strokes. 


\section{LEARNING THE CHINESE SCRIPT CAN BE EASY}

Every $\mathrm{dz}$, whether it is simple or complicated, occupies an equal square of space, marked or unmarked. One usually begins from the top left corner then proceeds towards either the bottom left corner

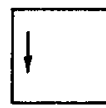

or the top right corner

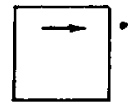

There are also different kinds of strokes and accepted stroke orders. For example: - is usually written from

the left to the right. | is usually written from the top to the bottom. $\quad$ is usually written with - first and $\quad$ next. $\square$ is usually written in three strokes. 1 first, 7 next, and - last. If there is anything written within $\square$, the last stroke, - , is usually not written until everything within is finished, leaving - to close the door. 人 is usually written with the first stroke, $\quad$, from top to the left and the second stroke, \, from the center to the right. Once the students learn these combinations, they will be able to see the parts in such $\mathrm{dz}$ as
a.
b. 杏 


\section{c. $\theta$ \\ d. $a$ \\ and<smiles>C1C2CC12</smiles>

and the stroke order in each part.

The arrangement of the parts follows a general overall pattern of finishing one part and then going on to the next. For example:
a. 説
b. 毒
1. 言
1. $三$
2. 言”
2. 灻
3. 言占
3. 春

\section{4. 説}

When students, who have gone through the accepted order, come across such a dz as , the task is not a matter of

remembering the different kind of strokes and the order of the 20 strokes. It has become a matter of remembering the arrangement of five small parts, each one of which is already within their experience. The five parts are:
1.
2. $a$
3. $\mathrm{R}$ 


\section{LEARNING THE CHINESE SCRIPT CAN BE EASY}
4. 羊
5. 凡

Teaching the accepted order of writing is also a means to an end. There are different styles of writing. Unless a certain order is followed, it will be difficult to transfer from one style to another. For example: The stroke order of 为 in the regular style (with no strokes omitted) is:

1.

2. $y$

3.

4. 为

5. 诌

6. 诌

7. 谄

8. 瓷

9. 掐

and in the cursive style (with many strokes running together) 䊏 is if 
The stroke order of $y$ in the regular style is:

1. $\mathrm{J}$

2. I

3.

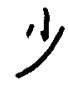

4. 少

In the cursive style, 少 is $\$$. The simplification is not accidental; it results automatically from the stroke-sequence in the regular style, as may easily be seen by inspection. And it is this that makes it possible to read the cursive, in spite of its seemingly having lost a large fraction of the many details of the regular style. Moreover, this is the reason for insisting on the regular sequence of strokes.

The last step is the arrangement of the $\mathrm{dz}$. The traditional way the $\mathrm{dz}$ are arranged in writing, as everyone knows, is from the top right corner of the page to the bottom left corner, downward in each column, the last column at the left. This has left its impress upon idiom: The Chinese will say "You said it upside down" when English speakers say "You said it backwards." However, the European pattern--left to right written lines, last line at the bottom--has increasingly come into use in this century, especially for readers with modern interests and in many texts which include a considerable amount of quotations from European languages, mathematics, chemistry, etc. Once a person has mastered the various steps, he is able to write in Chinese.

In conclusion, writing in Chinese must not be taught at the same time as speaking and reading. The process of writing, however, can be compared to the process of speaking. Speaking amounts to the manipulation of a system of the features of sounds; the arrangement of sounds into morphemes; the arrangement of morphemes into utterances; the arrangement of utterances into a speech. In other words, the language is the system. Writing in Chinese has its own system, made up of the kind of strokes, the arrangement of strokes into parts, the arrangement of parts into $\mathrm{dz}$, and the arrangement of $\mathrm{dz}$ into written utterances. 